\title{
GAMBARAN PERILAKU CYBERSEX PADA REMAJA PELAKU CYBERSEX DI KOTA MEDAN
}

\author{
Noni Novika Sari \\ Ridhoi Meilona Purba*
}

\begin{abstract}
ABSTRAK
Di dalam penelitian ini, kami mengeksplorasi gambaran perilaku cybersex pada remaja di kota Medan. Partisipan di dalam penelitian ini merupakan individu yang mengaku pernah melakukan kegiatan cybersex. Mereka kami rekruit secara insidental di beberapa warung internet (warnet) yang berlokasi di sekitar areal persekolahan dan universitas di kota Medan. Hasil penelitian ini menunjukkan bahwa $67 \%$ remaja yang melakukan aktivitas cybersex melakukan aktivitas tersebut dalam rangka rekreasi (recreational users), 29\% merupakan pengguna beresiko (at risk users), dan hanya 4\% merupakan pengguna kompulsif (sexual compulsive users). Penelitian ini juga menemukan bahwa alasan utama para remaja pelaku cybersex melakukan aktivitas cybersex adalah: (1) kemudahan dalam mengakses atau memperoleh materi seksual, (2) keterjagaan privasi, (3) dan kebebasan dalam mengekspresikan fantasi seksual.
\end{abstract}

Kata kunci: Cybersex; recreational users; at risk users; sexual compulsive users; remaja

\section{DESCRIPTIVE OF CYBERSEX BEHAVIOR AMONG ADOLESCENTS ENGAGING IN CYBERSEX IN MEDAN}

\begin{abstract}
In the present study, we examined descriptively cybersex behavior among adolescents in Medan. Participants in the current research were individuals who have been engaging in cybersex activity. They were recruited incidentally at several internet cafe located around schools and universities area in Medan. The results of this research showed that $67 \%$ adolescents who engage in cybersex were recreational users, $29 \%$ were at risk users, and only $4 \%$ were sexual compulsive users. This research also found several main reasons for adolescents to engage in cybersex: (1) ease of access to attain or accessing sexual materials, (2) privacy assurdness, (3) and the opportunity to express free sexual fantasy.
\end{abstract}

Keywords: Cybersex; recreational users; at risk users; sexual compulsive users; adolescents

\footnotetext{
* Korespondensi mengenai penelitian ini dapat dilayangkan kepada Ridhoi M. Purba melalui email: ridhoi.purba@gmail.com
} 
Internet sudah menjadi bagian yang tak terpisahkan dari evolusi sosialisasi manusia (Andini, 2006). Bagi orang-orang yang tinggal di kota, khususnya kota-kota yang ada di Indonesia, peran internet dijadikan kebutuhan informasi utama karena saat ini masyarakat kota cenderung haus akan informasi, apabila tidak mengenyam informasi satu hari saja rasarasanya hidup ini menjadi serba gelisah tak karuan dan takut dianggap ketinggalan zaman (Purwaningsih, 2008). Seperti semua kemajuan teknologi di masa lampau, internet dapat digunakan untuk tujuan baik dan buruk tergantung penggunanya (McKenna \& Bargh dalam Baron\& Byrne, 2000). Tjiptono dan Santoro (dalam Nainggolan, 2008) mengatakan, adapun tujuan yang baik tersebut adalah seperti untuk keperluan penelitian atau pengambilan keputusan organisasi, sedangkan tujuan yang buruk tersebut adalah seperti mengakses situssitus porno.

Kamus Besar Bahasa Indonesia (2001) mendefinisikan porno sebagai kependekan dari pornografi, yaitu penggambaran tingkah-laku secara erotis dengan lukisan atau tulisan untuk membangkitkan nafsu birahi seksual. Definisi ini sesuai dengan Malamuth dan Huppin (dalam Brown \& L'Engle, 2009) ang mendefinisikan pornografi sebagai media yang memperlihatkan seksual yang bertujuan untuk merangsang orang yang melihatnya. Sehubungan dengan ini, penggunaan internet sebagai alat ransangan seksual terus meningkat (Goldberg, 2008; Santrock, 2003). Peningkatan ini bisa terjadi karena semakin sadar seseorang terhadap hal-hal yan berkaitan dengan seksual, semakin besar usaha orang tersebut untuk mencari lebih banyak informasi mengenai seksual, internet merupakan sumber yang mudah dalam mengakses informasi seksual tersebut (Rahmawati, Hadjam, \& Afiatin, 2002).

Papu seorang Psikolog (dalam "Situs", 2001) menambahkan, dari seluruh jumlah pengguna internet di Indonesia, 50\% diantaranya tidak bisa menahan diri untuk tidak membuka situs porno. Berdasarkan hasil penelitian Daneback, Cooper, dan Mansson (2005) yang mengatakan bahwa yang paling banyak menggunakan internet untuk tujuan seksual adalah remaja, hal ini didukung pula oleh hasil penelitian Carvalheira dan Gomes (2002).

Pada Cerita Remaja Indonesia (dalam Supriati dan Fikawati, 2009) dinyatakan bahwa tayangan media massa yang menampilkan aspek pornografi mengakibatkan kekerasan seksual yang terjadi pada remaja. Sejalan dengan Kartono (2003) yang mengatakan bahwa rangsangan kuat dari film-film seks, sinetron, buku-buku bacaan dan majalah-majalah bergambar seksi, godaan dan rangsangan dari kaum pria, serta pengamatan secara langsung terhadap perbuatan seksual tidak hanya mengakibatkan memuncaknya atau semakin panasnya reaksi-reaksi seksual tetapi juga mengakibatkan kematangan seksual yang lebih cepat pada diri remaja.

Contohnya saja kasus video yang melibatkan artis-artis populer di Indonesia.Menurut ketua KPAI Hadi Supeno di Mabes Polri, peredaran video mesum yang melibatkan mantan vokalis grup musik Peterpan, yaitu Nazriel Irham alias Ariel, artis Luna Maya, dan Cut Tary, telah membuat tindak pidana pemerkosaan di Indonesia naik 20 persen setelah video tersebut beredar dalam kurun waktu satu minggu (dalam "Video", 2006). Kebanyakan kasus-kasus pemerkosaan paling banyak pelakunya adalah remaja laki-laki dan korbannya adalah remaja perempuan (Jufri, 2005).

Saat ini, video-video yang menampilkan aspek pornografi seperti yang dijelaskan sebelumnnya telah banyak beredar di internet. Internet digunakan untuk melakukan aktivitas yang menstimulasi dan memberikan kesenangan seksual. Aktivitas-aktivitas tersebut seperti melihat gambar-gambar erotis, terlibat dalam chatting tentang seks, saling tukar menukar gambar atau pesan email tentang seks yang kemudian disebut dengan cybersex (Cooper, 2002). Maheu (2001) juga mendefinisikan cybersex dengan lebih luas lagi, yaitu terjadi ketika orang menggunakan komputer yang berisi tentang teks, suara dan gambar yang didapatkan dari software atau internet untuk stimulus seksual dan secara khusus mencakup 
dua atau lebih orang berinteraksi di internet yang membangkitkan gairah seksual satu dengan yang lainnya.

Carners, Delmonico, dan Griffin (2001) mengkategorikan beberapa bentuk perilaku cybersex, yang pertama adalah mengakses pornografi di internet (seperti gambar, video, cerita teks, majalah, film, dan game). Mengakses pornografi di internet adalah hal yang paling mudah diakses oleh siapapun, apalagi perkembangan situs porno yang semakin hari semakin meningkat di internet (Carnes, Delmonico,\& Griffin., 2001). Hal ini didukung oleh Cooper (dalam Weiten \& Liyod, 2006) bahwa jumlah situs porno di dunia pada tahun 2000 terdapat sekitar 28.000 situs, dan pada tahun 2006 terjadi kenaikan sebanyak 100.000 situs. Sedangkan pada tahun 2007 terjadi lagi peningkatan sekitar 1,3 milliar situs porno di seluruh dunia yang terdapat di internet. Sedangkan di Indonesia sendiri jumlah situs porno meningkat dari 22.100 situs pada tahun 1997 menjadi 280.000 situs pada tahun 2000 atau melonjak 10 kali banyak dalam kurun waktu tiga tahun (Soebagijo, 2008). Cooper (2002) juga menegaskan bahwa seks ataupun hal-hal yang berbau porno menempati urutan pertama topik yang paling digemari dan dicari oleh para netter di Amerika. Kenyataannya di Indonesia sendiri tidak jauh berbeda (dalam "Cybersex", 2008). Hal ini didukung oleh Aziyz (2009) yang mangatakan bahwa berdasarkan Internet pornography statistic, untuk mengakses situs porno di Internet, Indonesia menempati peringkat ketujuh dunia setelah Pakistan, India, Mesir, Turki, Aljazair, dan Maroko. Namun kondisi ini terus meningkat menjadi peringkat kelima pada tahun 2007 dan menjadi peringkat ketiga pada tahun 2009.

Bentuk perilaku cybersex yang kedua adalah mengakses multimedia software yang tidak harus online (seperti menonton VCD/DVD video atau film porno dan memainkan game porno di laptop atau komputer). Peredaran VCD dan DVD porno saat ini semakin marak dan terbuka. Jual beli VCD dan DVD porno terjadi hampir disetiap sudut kota, bahkan tak jarang ditemukan hingga ke pedesaan. Mudah untuk mendapatkan VCD dan DVD porno semakin didukung oleh menjamurnya tempat-tempat penyewaan atau rental VCD dan DVD, dengan hanya membayar lima ratus, seribu hingga dua ribu rupiah, VCD dan DVD porno sudah dapat dipinjam semalaman di rumah ("Penjualan", 2004).

Bentuk perilaku cybersex yang terakhir adalah real time dengan pasangan fantasi atau chatting yang memuat obrolan erotis dengan teman chat di ruang mengobrol juga banyak diperbincangkan saat ini, bahkan beberapa orang sampai menggunakan kamera web untuk melihat pasangan mereka di ruang ngobrol (Carvalheira \& Gomes, 2002). Cooper dan Griffin-Shelley (dalam Daneback, Cooper, \& Mansson, 2005) mengatakan bahwa pada beberapa kasus, mereka saling tukar menukar gambar mereka sendiri atau gambar-gambar erotis dan gambar-gambar bergerak yang mereka dapat dari web internet. Biasanya orang yang terlibat dalam kasus ini tidak pernah ketemu sebelumnya di dunia nyata. Percakapan yang di lakukan oleh mereka mulai dari godaan dan kata-kata kotor untuk memberikan gambaran bahwa mereka sedang melakukan hubungan seksual, dan tak jarang dari mereka yang dapat merasakan orgasme, baik itu hanya dengan berfantasi melalui alam pikiran atau bisa juga diimbangi dengan melakukan onani atau masturbasi.

Cooper (2002) mengatakan bahwa ada 3 (tiga) komponen yang menyebabkan kenapa individu melakukan aktivitas cybersex yang disingkat dengan triple $A$ engine yaitu: accessibility, affordability, dan anonymity. Accessibility mengacu pada kenyataan bahwa internet menyediakan jutaan situs porno dan menyediakan ruang mengobrol yang akan memberikan kesempatan untuk melakukan cybersex. Affordability mengacu pada untuk mengakses situs porno yang disediakan internet tidak perlu mengeluarkan biaya mahal. Sedangkan Anonymity mengacu pada individu tidak perlu takut dikenali oleh orang lain. Carners, Delmonico dan Griffin (2001) menambahkan dua komponen yang menyebabkan kenapa individu melakukan perilaku cybersex yaitu isolation dan fantasy. Isolation mengacu padaindividu memiliki kesempatan untuk memisahkan dirinya dengan orang lain dan terlibat 
dalam fantasi apapun yang dipilih tanpa resiko seperti infeksi secara seksual atau gangguan dari dunia nyata. Sedangkan fantasy mengacu pada individu mendapatkan kesempatan untuk mengembangkan fantasi seksual tanpa takut akan ditolak.

Delmonico (dalam Laws \& O’Donohue, 2008) juga menyatakan bahwa cybersex dapat digambarkan berdasarkan tingkat permasalahan yang ditampilkannya melalui suatu alat ukur Internet Sex Screening Test (ISST), dapat dilihat gambaran perilaku yang kemudian digunakan sebagai self-administered untuk menggambarkan tingkat masalah perilaku cybersex. Internet Sex Screening Test (ISST) tersebut terdiri dari 25 aitem yang penyusunannya terdiri dari 5 (lima) faktor dan ditambah lagi dengan 2 (dua) single item, yaitu: pertama, Online Sexual Compulsivity, mengukur indikator dari perilaku cybersex yang kompulsif, termasuk lanjutan dari cybersex yang berkonsekuensi terhadap kehidupan nyata. Kedua, Online Sexual Behavior Social, mengukur perilaku cybersex yang terjadi dalam konteks hubungan sosial atau melibatkan interaksi interpersonal dengan orang lain ketika online (seperti ruang mengobrol (chat room), dan email). Ketiga, Online Sexual Behavior Isolation, mengukur perilaku cybersex yang terjadi tanpa ada hubungan sosial di dalamnya dan melibatkan interaksi interpersonal yang terbatas. Keempat, Online Sexual Spending, mengukur banyaknya uang yang dikeluarkan individu untuk aktivitas cybersex, dan konsekuensi yang berhubungan dengan pengeluaran tersebut. Kelima, Interest in Online Sexual Behavior, mengukur kecenderungan untuk menggunakan komputer untuk tujuan seksual (seperti menandai situs seksual).Adapun 2 (dua) single item tersebut adalah non-home use of the internet dan illegal online behavior. Non-home use of the internet, mengukur kecenderungan untuk mengakses situs seksual dari komputer lain selain komputer yang ada di rumah. Illegal online behavior, mengukur kecenderungan untuk melihat materi seksual illegal di internet.

Cooper, Delmonico, dan Burg (dalam Carners, Delmonico \& Griffin, 2001) mengkategorikan 3(tiga) kategori individu yang melakukan perilaku cybersex yaitu: Recreational users, At-risk users, Sexual Compulsive users. Recreational users yaitu individu yang mengakses materi seksual karena keingintahuan atau untuk hiburan dan merasa puas dengan ketersediaaan materi seksual yang diinginkan. Pada individu juga ditemukan adanya masalah yang berhubungan dengan perilaku mengakses materi seksual. Dari penelitian yang dilakukan maka ditemukan bahwa individu yang masuk ke dalam kategori recreational users mengakses situs yang berkaitan dengan seksual kurang dari 1 jam per minggu dan sedikit konsekuensi negatif. At-risk users yaitu ditujukan pada orang yang tanpa adanya seksual kompulsif, tetapi mengalami beberapa masalah seksual setelah menggunakan internet untuk mendapatkan materi seksual. Individu menggunakan internet dengan kategori waktu yang moderat untuk aktivitas seksual dan jika penggunaan yang dilakukan individu berkelanjutan, maka akan menjadi kompulsif. Sexual compulsive users yaitu individu menunjukkan kecenderungan seksual kompulsif dan adanya konsekuensi negatif, seperti merasakan kesenangan/keasikan terhadap pornografi, menjalin hubungan percintaan dengan banyak orang, melakukan aktivitas seksual dengan banyak orang yang tidak dikenal, karena menggunakan internet sebagai forum atau tempat untuk aktivitas seksual, dan yang lainnya berdasarkan DSM-IV.

Bagi sebagian besar remaja, fenomena cybersex ini dianggap masih sangat tabu dan merupakan perilaku seksual yang tidak lazim. Namun ada juga yang menganggap perilaku ini dianggap sebagai suatu cara yang paling aman untuk menyalurkan hasrat seksualnya (Pribadi \& Putri, 2009). Didukung oleh hasil penelitian Pustaka Komunikasi FISIP UI (dalam Darmasih, 2008), menunjukkan bahwa ketersediaan dan kemudahan menjangkau produk media massa yang dapat membangkitkan nafsu birahi secara seksual merupakan faktor stimulan utama bagi remaja untuk melakukan perilaku tersebut di dunia nyata. 
Menurut hasil survei yang dilakukan oleh Dr. Patricia Goodson pada tahun 2001 bersama rekan-rekannya di Texas A \& M University terhadap 506 siswa perguruan tinggi pengguna internet, dan hasilnya telah diterbitkan pada jurnal Archieves of Sexual Behavior yang menunjukkan bahwa sebanyak $44 \%$ remaja mengatakan telah memasuki materi seksual dengan jelas melalui internet. Sekitar 57\% remaja yang berjenis kelamin laki-laki betul-betul melakukannya dibanding 35\% remaja yang berjenis kelamin perempuan. Hanya 3\% dari jumlah remaja secara keseluruhan yang masuk ke materi seksual ini secara teratur dan lebih banyak yang berjenis kelamin laki-laki melakukan masturbasi pada saat online (15\%). Namun demikian diperoleh data yang cukup mengejutkan yaitu 5\% remaja yang berjenis kelamin perempuan melaporkan telah melakukan cybersex dengan pasangan online-nya dibandingkan remaja yang berjenis kelamin laki-laki yang hanya 3\%(dalam Pribadi \& Putri, 2009).

Berdasarkan uraian diatas, perilaku cybersex adalah fenomena seks yang baru dan fenomena yang sedang marak diperbincangkan dalam perkembangan teknologi Internet, perilaku cybersex tersebut semakin hari semakin banyak penggemarnya terutama pada remaja. Pada kasus-kasus pemerkosaan yang pelakunya sebagian besar adalah remaja lakilaki dan korbannya adalah remaja perempuan yang penyebabnya adalah karena mengakses situs-situs seksual di internet (cybersex). Untuk itu peneliti tertarik untuk mengadakan penelitian dalam rangka mengetahui gambaran perilaku cybersex pada remaja.

\section{METODE}

\section{Partisipan}

Partisipan dalam penelitian ini adalah 83 orang remaja (43 laki-laki, 40 perempuan) yang berusia antara 12 sampai 21 tahun, pernah melakukan cybersex dan bersedia untuk berpartisipasi dalam penelitian ini. Para partisipan merupakan siswa tingkat sekolah menengah pertama, sekolah menengah atas, dan perguruan tinggi yang direkruit di beberapa warung internet di sekitar kota Medan.

\section{Alat ukur}

Pengumpulan data dalam penelitian ini dilakukan dengan menggunakan metode survei. Dalam metode survei, kita langsung bertanya kepada partisipan mengenai perilakunya (dulu atau sekarang) (Borderns \& Abbot, 2005). Alat ukur yang digunakan berupa angket. Angket terdiri dari dua bagian. Bagian pertama berisi identitas responden, dan inform consent. Identitas responden berisi inisial, jenis kelamin, usia, dan status tempat tinggal. Bagian kedua terdiri dari 25 aitem Internet Sex Screening Test (ISST). ISST disusun oleh Delmonico (dalam Laws \& O’Donohue, 2008) yang selain digunakan sebagai selfadministered, juga untuk menggambarkan tingkat masalah perilaku cybersex. Aitem-aitem dalam alat ukur ini dibuat dengan dua pilihan jawaban $(1=$ " $y a$ ", $0=$ "tidak"). Metode skoring yang digunakan dalam penelitian ini adalah, setiap respon 'ya' menjawab "ya" mendapat skor 1. Sehingga skor minimum yang mungkin adalah 1 sedangkan skor maksimum adalah 25. Jika subjek menjawab 1 sampai dengan 8 aitem dari 25 aitem ISST maka akan dikategorikan ke dalam recreational users, jika menjawab 9 sampai dengan 18 aitem maka akan dikategorikan ke dalam at-risk users, dan jika menjawab lebih dari 19 aitem maka akan dikategorikan ke dalam sexual compulsive users. Adapun untuk enam aitem yang disusun oleh peneliti ditabulasikan sehingga diperoleh frekuensi dan persentase dari masingmasing jawaban subjek penelitian.

Selanjutnya, alat ukur ini terdiri dari tujuh bentuk perilaku cybersex. Untuk mempermudah proses analisis data, kami menggunakan simbol angka romawi sebagai indikator setiap bentuk perilaku cybersex. Simbol "I" berarti online sexual compulsivity, simbol "II" berarti online sexual behavior social, simbol"III" berarti online sexual behavior 
isolation, simbol "IV" berarti online sexual spending, simbol"V"berarti interest in online sexual behavior, simbol "VI" berarti non-home use of the internet, dan simbol "VII" pada illegal online behavior. Jadi, ketika seorang hanya memberikan respon "ya" pada aitem-aitem online sexual compulsivity dan non-home use of the internet, namun memberikan respon "tidak" pada aitem-aitem bentuk perilaku lainnya, maka kategori respon orang tersebut adalah I, VI.

Selain menggunakan ISST, kami juga menanyakan beberapa pertanyaan tambahan. Pertanyaan tambahan yang diajukan adalah:

1. "Apakah media yang anda gunakan ketika melakukan interaksi langsung (real time) dengan pasangan fantasi anda?" Pertanyaan ini dibuat dengan dua pilihan jawaban ("telepon", "kamera web")

2. "Apakah alasan anda melakukan perilaku cybersex? Pertanyaan ini dibuat dengan 9 pilihan jawaban ("Mudah diakses", "Biaya yang dikeluarkan sedikit", "Tidak ada yang mengganggu", "Tidak ada yang mengenali atau melihat", "Bebas mengekspresikan fantasi seksual tanpa harus takut ditolak oleh orang lain", "Aman dari penyakit", "Cara yang mudah untuk menemukan orang yang memiliki pandangan dan ketertarikan seksual yang sama", "Lainnya").

3. Dari manakah sumber untuk anda mendapatkan materi untuk melakukan cybersex secara online? Pertanyaan ini dibuat secara terbuka, sehingga partisipan dapat memberikan informasi sebanyak-banyaknya.

4. Dari manakah sumber untuk anda mendapatkan materi untuk melakukan cybersex secara offline? Pertanyaan ini dibuat dengan empat pilihan jawaban ("Meminjam dari teman/sudara", "Teman", "Lainnya").

\section{Prosedur}

Pengambilan datadilakukan pada bulan November 2010 di beberapa warnet yang berada di dekat sekolah SMP, SMA, dan Perguruan Tinggi di Medan, Sumatera Utara. Angket yang sudah di kopi sebanyak 120 eksemplar, disebar pada remaja yang mengunjungi warnet-warnet tersebut, baik itu siswa SMP maupun siswa SMA yang masih berpakaian sekolah, sedangkan pada pengunjung warnet yang tidak mengenakan pakaian sekolah, kami menanyakan usia dan kesediaan individu tersebut untuk mengisi angket. Pada saat penyebaran angket tersebut.Banyak individu yang pada awalnya menolak untuk berpartisipasi, karena mereka melihat isi angket yang pertanyaannya menyangkut seksualitas. Namun, sebagian dari mereka berhasil kami yakinkan bahwa ini hanyalah sebuah penelitian yang kerahasiaannya terjaga dan mereka berpartisipasi secara anonim. Setelah 120 angket tersebut disebar, kami memilih data partisipan yang benar-benar melakukan perilaku cybersex, dan dari 120 orang partisipan terdapat 83 orang yang melakukan perilaku cybersex.

\section{HASIL}

\section{Perilaku cybersex berdasarkan ISST}

Seperti tergambarkan pada Tabel 5, dapat dilihat bahwa dari 83 partisipan, sebanyak 21 orang $(25 \%)$ yang melakukan empat perilaku cybersex. Dari 21 orang tersebut, 10 orang melakukan kombinasi perilaku online sexual compulsivity, online sexual behavior social, online sexual behavior isolation, dan interest in online sexual behavior. Selanjutnya, diperoleh paling sedikit tiga orang $(4 \%)$ yang melakukan tujuh perilaku cybersex. Dengan melihat keseluruhuan kombinasi perilaku, dapat dilihat bahwa kemunculan perilaku online sexual compulsivity sangat frekuentif. Ini menunjukkan bahwa hampir semua partisipan melakukan perilaku online sexual compulsivity. Dari Tabel 5, dapat dilihat pula bahwa sebanyak 56 orang (67\%) partisipan merupakan recreational users, 24 orang 
(29\%)merupakan at risk users, dan hanya tiga orang (4\%) yang terkategorikan sebagai sexual compulsive users.

Tabel 1. Bentuk-bentuk perilaku dan kategori pengguna cybersex

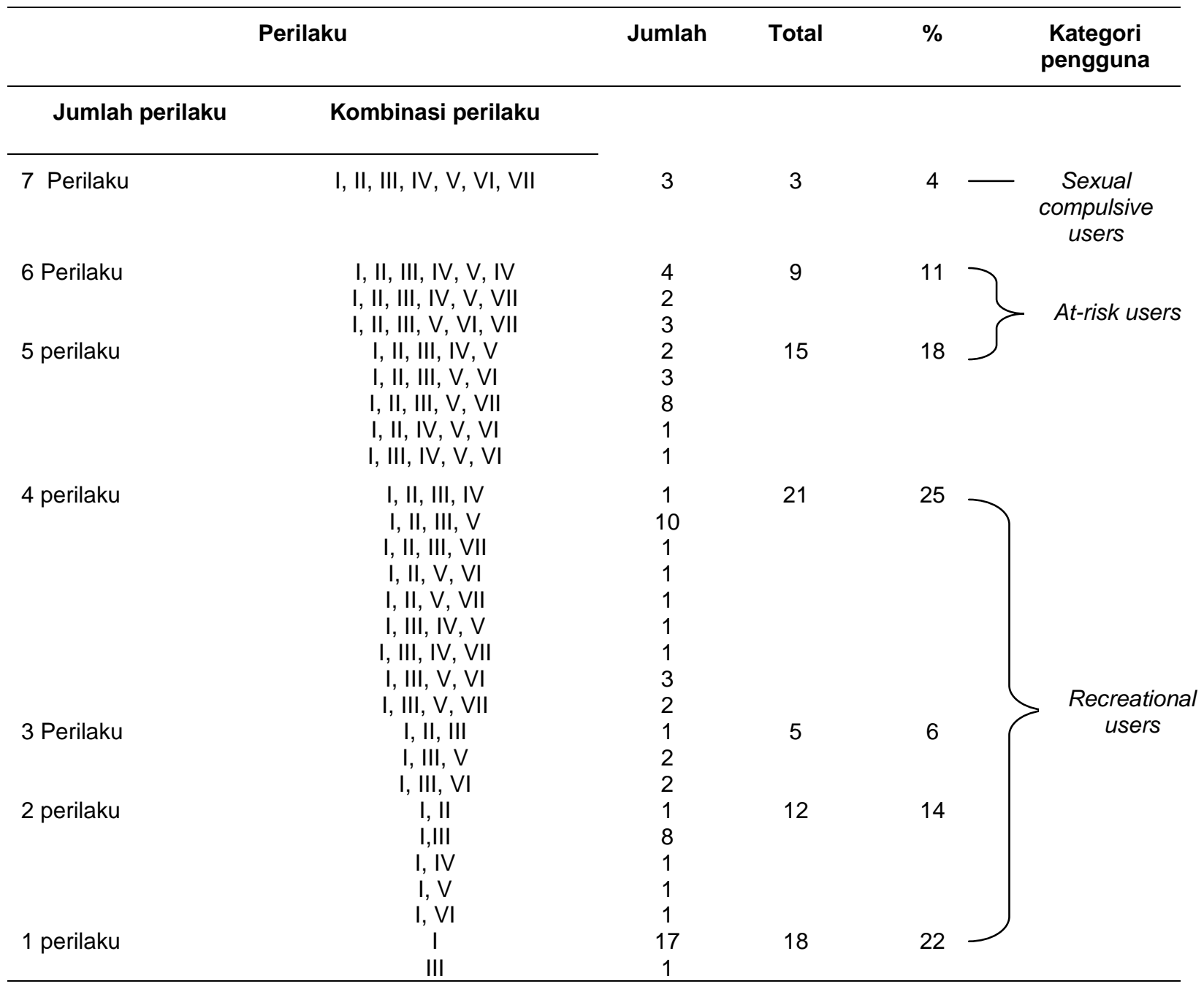

Media yang digunakan ketika berhubungan real-time dengan pasangan fantasi

Secara keseluruhan, hanya 21 orang (25\%) partisipan yang mengaku melakukan aktivitas cybersex secara real-time dengan pasangan fantasinya. Dari 21 orang tersebut, media yang paling banyak digunakan oleh para partisipan ketika terlibat dalam interaksi yang bersifat real-time dengan pasangan fantasi adalah telepon (12 orang, 57\%) dan yang menggunakan telepon adalah sebanyak sembilan orang (43\%).

\section{Alasan melakukan cybersex}

Dari 83 partisipan penelitian, diperoleh sebanyak 151 respon alasan melakukan perilaku cybersex, yang mana rata-rata partisipan memilih satu sampai dua respon. Adapun alasan-alasan tersebutdapat dilihat pada Tabel 2. Sesuai dengan Tabel 2, secara umum, alasan yang paling utama melakukan cybersex adalah karena kemudahan dalam mengakses konten seksual dengan biaya yang relatif kecil. 
Tabel 2. Alasan melakukan cybersex

\begin{tabular}{|c|c|c|c|}
\hline No. & Alasan & Frekuensi & $\%$ \\
\hline 1 & Mudah untuk diakses & 52 & 34 \\
\hline 2 & Biaya yang dikeluarkan sedikit & 36 & 24 \\
\hline 3 & Tidak ada yang mengganggu & 22 & 15 \\
\hline 4 & Tidak ada yang mengenali atau melihat & 16 & 11 \\
\hline 5 & $\begin{array}{l}\text { Bebas mengekspresikan fantasi seksual tanpa harus takut ditolak } \\
\text { oleh orang lain }\end{array}$ & 10 & 7 \\
\hline 6 & Aman dari penyakit & 6 & 4 \\
\hline 7 & $\begin{array}{l}\text { Cara yang mudah untuk menemukan orang yang memiliki } \\
\text { pandangan dan ketertarikan seksual yang sama }\end{array}$ & 5 & 3 \\
\hline 9 & Lainnya & 4 & 3 \\
\hline
\end{tabular}

Sumber materi untuk melakukan cybersex

\section{Sumber online}

Dari 83 responden, sebanyak 165 respon tentang alamat situs- situs yang bernuansa seksual yang dikunjungi. Adapun situs-situs seksual yang paling banyak dikunjungi oleh subjek penelitian dapat dilihat pada daftar Tabel 3.

Tabel 3. Sepuluh besar situs untuk melakukan cybersex

\begin{tabular}{clcc}
\hline No & Sumber & Frekuensi & $\%$ \\
\hline 1 & Youtube & 27 & 16 \\
2 & Porno & 20 & 12 \\
3 & Youporn & 17 & 10 \\
4 & Tube8 & 16 & 10 \\
5 & Google & 12 & 7 \\
6 & Worldsex & 11 & 7 \\
7 & Lalat X & 8 & 5 \\
8 & Red Tube & 7 & 4 \\
9 & Naughty America & 6 & 4 \\
10 & Cerita seks & 5 & 3 \\
11 & Lainnya & 36 & 22 \\
\hline
\end{tabular}

\section{Sumber offline}

Mengenai sumber darimanakah responden mendapatkan materi seksual offlline atau multimedia software yang bernuansa seksual (seperti DVD atau VCD erotis), dari 83 responden penelitiandiperoleh jumlah keseluruhan respon sebanyak 105 respon. Adapun sumber-sumber tersebut adalah meminjam multimedia software dari teman atau saudara secara gratis (59 respon, 56\%), membeli (22 respon, 21\%), menyewa (20 respon, 19\%), mengunduh untuk kemudian diakses secara offline (4 respon, $4 \%$ ).

\section{DISKUSI}

Dacey dan Kenny (1997) mengatakan bahwa pada masa remaja, dorongan seksual meningkat dalam bentuk keinginan untuk mendapatkan kepuasan seksual. Didukung oleh Rahmawati (2002) yang menegaskan bahwa semakin sadarnya remaja terhadap hal-hal yang berkaitan dengan seksual, semakin mereka akan berusaha mencari lebih banyak informasi 
mengenai seksual, termasuk informasi tentang seksual yang begitu mudah didapat dari internet.

Hasil penelitian ini menunjukkana bahwa mayoritas partisipan melakukan setidaknya empat dari tujuh perilaky cybersex. Dengan kombinasi perilaku online sexual compulsivity, online sexual behavior social, online sexual behavior isolation, dan interest in online sexual behavior sebagai kombinasi perilaku terbanyak. Jika dilihat secara keseluruhan hampir semua responden melakukan online sexual compulsivity.Hurlock (1994) mengatakan bahwa pada kelompok remaja masih labil dan belum mampu mengontrol diri, ketika terangsang dengan sajian yang berbau erotis membuat remaja tidak mampu menahan dorongan seksualnya. Pornografi bagi remaja merupakan sesuatu yang baru dan sangat menarik perhatian, semakin menarik informasi media pornografi semakin banyak pengulangan informasi seksualitas yang terjadi (Supriati \& Fikawati, 2009).

Hasil penelitian juga menemukan subjek penelitian paling banyak masuk ke dalam kategori recreational users. Cooper, Delmonico, dan Burg (dalam Carners, Delmonico \& Griffin, 2001) mengatakan bahwa individu yang mengakses materi seksual untuk memenuhi rasa ingin tahu atau untuk hiburan dan merasa puas dengan ketersediaaan materi seksual yang diinginkan. individu melakukan cybersex semata-mata untuk kenikmatan fisik yang mana orgasme merupakan tujuan utamanya (dalam Widyastuti, 2009).

Meninjau kedua hasil di atas, dapat disimpulkan bahwa responden dalam penelitian ini pada umumnya melakukan online sexual compulsivity, tetapi untuk tujuan rekreasi. Artinya, mereka melakukan cybersex secara berulang, dan sulit untuk berhenti atau tidak dapat mengendalikan diri untuk tidak melakukannya tetapi hal ini dilakukan hanya untuk hiburan semata. Saat mereka memiliki waktu luang, cybersex merupakan alternative hiburan yang dapat mereka nikmati.

Hasil penelitian ini juga menunjukkan bahwa alasan utama melakukan cybersex adalah kemudahan untuk mengakses. Hal ini sesuai dengan teori sebelumnya dari Carners, Delmonico, dan Griffin (2001) bahwa materi seksual di internet (secara online) sangat mudah diakses dibandingkan di dunia nyata. Menurut Cooper (2002) cybersex sangat mungkin terjadi karena situs-situs seksual mudah untuk diakses, kapan saja selama 24 jam sehari dan 7 hari seminggu, dan dimana saja seperti di sekolah, di kafe, di perpustakaan, di rumah, di tempat umum, dan tempat-tempat lainnya.

Adapun hasil penelitian ini juga mendapatkan bahwa beberapa situs yang paling banyak dikunjungi oleh subjek penelitian untuk mencari materi seksual adalah Youtube, Porno, Youporn, Tube8, Google, World Sex, Lalat X, Red Tube, Americasex, dan Ceritaseks. Hal ini sesuai dengan pernyataan Cooper (dalam Weiten \& Liyod, 2006) bahwa jumlah situs porno di dunia pada tahun 2000 terdapat sekitar 28.000 situs, dan pada tahun 2006 terjadi kenaikan sebanyak 100.000 situs. Sedangkan pada tahun 2007 terjadi lagi peningkatan sekitar 1,3 milliar situs porno di seluruh dunia yang terdapat di internet. Sedangkan di Indonesia sendiri jumlah situs porno meningkat dari 22.100 situs pada tahun 1997 menjadi 280.000 situs pada tahun 2000 atau melonjak 10 kali lebih banyak dalam kurun waktu tiga tahun (Soebagijo, 2008).

Perilakucybersex mulai dari melihat gambar-gambar erotis sampai dengan chatting erotis atau komunikasi real-time dengan pasangan fantasi. Ketika responden penelitian terlibat real-time dengan pasangan fantasi, mayoritas respondenmelakukannya dengan saling tukar menukar suara melalui media telepon. Delmonico, Carners, dan Griffin (2001) mengatakan bahwa ketika dua orang yang sedang mengobrol tentang seks secara online dan real-time, mereka dapat saling tukar menukar suara dengan menggunakan media telepon. Cooper (2000) mengatakan bahwa perilaku cybersex dalam bentuk real-time dengan pasangan online akan berlanjut ke phone sex atau seks via telepon. 
Adapun sumber-sumber subjek mendapatkan media-media seksual seperti multimediasoftware adalah dengan meminjam gratis dari teman. Hal ini sesuai dengan pernyataan Santrock (2003) yang menyatakan bahwa teman sebaya merupakan sumber informasi seks yang paling umum bagi remaja. Hurlock (1999) menambahkan bahwa masa remaja adalah masa dimana uang saku mereka masih diberi oleh orangtua, dan pada umumnya mereka memiliki uang saku yang terbilang pas-pasan, sehingga untuk sumber materi seksual yang dibutuhkan lebih memilih untuk meminjam gratis dari teman.

\section{Saran}

Peneliti menyadari bahwa penelitian ini masih jauh dari kesempurnaan, oleh karena itu, maka peneliti mengemukakan beberapa saran. Saran-saran ini diharapkan dapat berguna untuk penelitian selanjutnya yang berhubungan dengan perilaku cybersex pada remaja.

\section{Saran Metodologis}

a. Penelitian selanjutnya dengan tema yang sama diharapkan menambahkan variabel lain yang berhubungan dengan perilaku cybersex, seperti pola asuh orang tua, orientasi seksual, tingkat keingintahuan tentang materi seksual, tingkat kepuasan seksual, rasa bersalah dan variabel lainnya.

b. Pada penelitian selanjutnya, diharapkan dapat lebih memperhatikan sampel agar lebih representatif, seperti dengan menggunakan teknik pengambilan sampel yang berbeda.

c. Sebaiknya dalam penelitian selanjutnya di samping melakukan penelitian secara kuantitatif, perlu juga dilakukan penelitian secara kualitatif untuk lebih mengetahui perilaku cybersex yang dilakukan oleh remaja secara mendalam.

d. Pada peneliti selanjutnya, sebaiknya aitem yang ada di dalam angket harus lebih diperhatikan lagi, sehingga tidak kesulitan ketika melakukan pengolahan data. Jangan membedakan halaman antara aitem di bagian satu dengan bagian dua karena subjek penelitian tidak mengetahui terdapat aitem-aitem bagian dua yang ada di halaman selanjutnya sehingga aitem di bagian dua tersebut tidak di beri jawaban.

\section{Saran praktis}

a. Bagi remaja diharapkan agar mengurangi kegiatan melakukan aktivitas cybersex karena memberikan pengaruh terhadap diri sendiri, kehidupan mereka sehari-hari dan lingkungan di sekitar seperti lebih sering mengasingkan diri dari orang lain, menghindari pekerjaan atau tugas-tugas di sekolah maupun di rumah.

b. Bagi remaja, agar bersikap hati-hati dalam menyikapi semakin berkembangnya jumlah situs-situs seks di internet dan maraknya penjualan VCD/DVD porno yang semakin luas dan bebas, karena perkembangan ini sulit dicegah, tetapi dapat dikontrol dan mengendalikan efeknya melalui usaha-usaha pengembangan diri seperti meningkatkan kontrol diri, mengembangkan kebiasaan-kebiasaan yang positif.

c. Bagi orangtua dapat memberikan bimbingan dan pengawasan yang lebih kepada anaknya dalam menggunakan internet atau komputer, serta memberikan penjelasan tentang keuntungan dan kerugian menggunakan internet atau komputer tersebut.

d. Bagi para orangtua, jangan tabu untuk membicarakan masalah yang berkaitan dengan seksual, terutama kepada anaknya yang memasuki usia remaja, sebab jika tidak maka remaja dapat saja mencari informasi tersebut di luar karena didorong oleh rasa ingin tahu dan penasaran.

e. Bagi para orangtua, sebaiknya lebih memperhatikan perilaku yang dilakukan oleh anaknya terutama jika sudah menginjak usia remaja.

f. Sebaiknya orangtua dapat menjadi sahabat bagi anaknya, terutama ketika anak menginjak usia remaja, sehingga mereka akan lebih terbuka dan semakin percaya untuk menceritakan segala sesuatunya, terutama hal-hal yang berkaitan dengan 
seksual, dan akhirnya orangtua dapatlah mengontrol apa yang dilakukan remaja tersebut.

g. Selain orang tua, guru dan seseorang yang ahli, baik di sekolah maupun di luar sekolah juga perlu memberikan informasi dan pemahaman mengenai hal-hal yang berkaitan dengan seksual pada remaja, sehingga keingintahuan remaja terhadap masalah seksual dapat terpenuhi tanpa harus mencari informasi tersebut dari sumber yang salah.

h. Bagi lembaga pemerintah, harus lebih mengawasi dan mengantisipasi lagi perkembangan situs-situs porno di internet yang semakin meningkat dan peredaran VCD/DVD porno yang semakin luas serta bebas beredar di lingkungan sekitar remaja.

i. Bagi pengelola warnet dan penjual atau penyewa VCD/DVD porno, agar tidak hanya memperhitungkan keuntungan dari sisi bisnis, tetapi juga membantu para remaja agar tidak memiliki kesempatan untuk melakukan perilaku yang tidak diinginkan seperti perilaku cybersex.

\section{DAFTAR PUSTAKA}

Andini, S. (2006). Perbedaan sikap terhadap cybersex berdasarkan jenis kelamin pada dewasa awal. Skripsi yang tidak dipublikasikan, Universitas Gunadarma, Fakultas Psikologi, Jakarta, Indonesia.

Baron, R. A., \& Byrne, D. (2000). Social psychology (ed. ke-9). U.S.A.: Allyn \& Bacon.

Video “Ariel-Cut Tary”. (2006). Diambil dari http://bataviase.co.id/node/244979

Bordens, S. K. \& Abbott, B. B. (2005). Research design and methods (ed. ke-6). N. Y.: McGraw Hill.

Brown, J . D., \& L'Engle, K. L. (2009). X-Rated sexual attitudes and behaviors associated with U.S. early adolescents' exposure to sexually explicit media. Communication Research, 36(1), 129-151. doi: 10.1177/0093650208326465

Carners, P. J., Delmonico, D. L., \& Griffin, E. J. (2001). In the shadows of the net. Center City: Hazelden Foundation.

Carvalheira, A. A., \& Gomes, F.A. (2002). Cybersex in Portuguese chatrooms a study of sexual behaviors related to online sex. Brunner-Routlege.

Cooper, A. (2002). Sex and the internet. U.S.A.: Brunner-Routledge.

Cooper, A., Scherer, C., Boies, S. C., \& Gordon, B. L. (1999). Sexuality on the internet from sexual exploration to pathological expression. Professional Psychology: Research and Practice, 30(2), 154-164.

Dacey \& Kenny (1997). Adolescent development (ed. ke-2). USA: Brown \& Benchmark Publishers.

Daneback, Cooper, \& Mansson (2004). An internet study of cybersex participants.Business Media, Inc.

Daneback, K. (2006). Love and sexuality on the internet. A qualitative approach. Goteborg: Goteborg University

Darmasih, R. (2009). Faktor yang mempengaruhi perilaku seks pranikah pada remaja SMA di Surakarta. Skripsi yang tidak dipublikasikan, Universitas Muhammadiyah, Surakarta, Indonesia. 
Situs porno dan kesehatan mental. (2001). Diambil dari http://www.epsikologi.com/dewasa/cybersex.htm.

Golberg, P. D. (2004). An exploratory study about the impacts that cybersex (the use of the internet for sexual purposes) is having on families and the practices of marriage and family therapists. Tesis master yang tidak dipublikasikan, Virginia Polytechnic Institute and State University, Falls Church, Virginia, U.S.A.

Hasan., dkk. (2003). Kamus besar bahasa Indonesia. Jakarta: Balai Pustaka

Hurlock, E. (1994). Psikologi perkembangan: suatu pendekatan sepanjang rentang kehidupan. Jakarta: Penerbit Erlangga.

Hurlock, E. (1999). Psikologi perkembangan: suatu pendekatan sepanjang rentang kehidupan. Jakarta: Penerbit Erlangga.

Penjualan VCD porno merambah ke sekolah. (2004). Diambil darihttp://www.indosiar.com/fokus/27589/penjualan-vcd-porno-merambah-ke-sekolahsekolah

Jufri, M. (2005). Intensitas mengakses situs seks dan permisivitas perilaku seksual remaja. Jurnal Intelektual, 2, 107-120.

Laws, D.R., \& O’Donohue, W.T. (2008). Sexual deviance: Theory, assessment, and treatment. New York: Guilford Press.

Maheu. (2001). Etiology and treatment of internet-related problems. Pioneer Depelovement Resource, Inc.

Nainggolan, M. (2008). Dampak Internet terhadap sosial individu. Diambil darihttp://munawarohnainggolan.blogspot.com/

Cybersex: sarana ekspresi. (2008). Diambil darihttp://lifestyle.okezone.com/index.php/ReadStory/2008/10/11/24/152914/24/cybersex-sarana-ekspresi

Pribadi, S.A \& Putri, D.E. (2009). Perbedaan sikap terhadap cybersex pada mahasiswa ditinjau dari jenis kelamin.Skripsi yang tidak dipublikasikan, Universitas Gunadarma, Fakultas Psikologi, Jakarta, Indonesia.

Purwaningsih, R. (2008). Cybersex dikalangan remaja. Skripsi yang tidak dipublikasikan, Universitas Muhammadiyah, Surakarta, Indonesia.

Rahmawati, D., Hadjam, N., \& Affiatin, T. (2002). Hubungan antara kecenderungan perilaku mengakses situs porno dan religiusitas remaja. Jurnal Psikologi, 1, 1-13.

Santrock, J. W. (2003). Adolescence: Perkembangan remaja (ed. ke-6). Jakarta: Erlangga.

Soebagijo, A. (2008). Pornografi: Dilarang tapi dicari. Jakarta: Gema Insani.

Supriati, E., \& Fikawati, S. (2009). Efek Paparan Pornografi Pada Remaja SMP Negeri Kota Pontianak Tahun 2008. Makara, Sosial Humaniora, 13(1). Weiten, W \& Llyod, M. (2006). Psychology applied to modern life: Adjustment in the 21st Century (ed. ke-8). Canada: Thomson Wadsworth.

Widyastuti. (2009). Kesehatan reproduksi. Yogyakarta: Fitra Maya. 